\title{
Research Note: Validating INDSERV (Industrial Service Quality) Scale in Business to Business Context: A Study Based on the Sri Lankan Hotel Sector
}

\author{
Nilakshi W K Galahitiyawe and Ghazali Musa
}

\begin{abstract}
Service quality is generally measured on the SERVQUAL scale, developed by Parasuraman, Berry \& Zeithaml (1985). However, the appropriateness of SERVQUAL is disputed as it is specifically designed for the B2C (business-tocustomer) context (Gounaris 2005a, 2005b, Lee 2011). Thus, Gounaris (2005a, 2005b) developed an instrument called INDSERV that specifically measures business-to-business (B2B) service quality performance. The purpose of this study is to validate the INDSERV scale in Sri Lanka as well. Cross-sectional data of service quality in the outsourcing context was collected through a survey of managers in the hotel sector in Sri Lanka using self-administered structured questionnaires. A total of 183 usable responses were collected. Unidimensionality, reliability and validity of the scale were assessed accordingly. Among the four dimensions of the scale, Hard Process Quality shows the highest contribution on the vendors' service quality performance ( $\beta=0.98)$ followed by Output Quality $(\beta=0.86)$. Statistical tests were proposed to exclude the 'potential service quality' dimension from the scale as it reported weak reliability ( $\alpha=0.25$, all item total correlations were below 0.1 ). There were 22 items in the INDSERV scale and the refined model contains only 12 items. In conclusion, this study identified the need for a field survey to uncover unique factors that measure industrial service quality in Sri Lanka as it may be a reason for the contextual mismatch of a borrowed scale.
\end{abstract}

Keywords: business-to-business, INDSERV, outsourcing, service quality.

Nilakshi W K Galahitiyawe, $\boldsymbol{P h D}$ is a Senior Lecturer of the Department of Decision Sciences, Faculty of Management Studies and Commerce, University of Sri Jayewardenepura. E-mail: nilakhsi@sjp.ac.lk. (Corresponding author)

Ghazali Musa, $\boldsymbol{P h D}$ is a Professor in Tourism and Head, Department of Strategy and Policy, Faculty of Business and Accountancy at the University of Malaya, Malaysia. 


\section{NSBM Journal of Management}

Vol. 1, No. 1, January - June, 2015

\section{Introduction}

Collaboration among firms enhances their respective competitiveness and develops their resource bases (Al-Natour \& Cavusoglu 2009), which can be in the form of strategic alliances, mergers, partnerships or outsourcing. It is imperative that any form of collaboration relies on the strength of the members' relationship beyond traditional purchasing. With regard to the upstream supply chain of service firms, vendors play a major role in satisfying customers.

The vendor's performance basically includes quality and other performance specifications. They are generally evaluated through SERVQUAL scale (Parasuraman, Berry \& Zeithaml, 1985, 1988). But, it appears to perform weaker in business to business (B2B) contexts (Gounaris 2005a, 2005b, Lee 2011). Alternatively, Gounaris (2005a, 2005b) developed a measurement scale to evaluate vendor's service performance known as INDSERV. This is widely accepted for the evaluation of service performance in the B2B context. The scale comprises four service quality dimensions that a firm expects from its B2B business partners: potential quality, hard process quality, soft process quality and output quality. Together, these dimensions explain 22 aspects (items) of service quality and other performance expectations. This study investigates the outsourcing practices of the service sector in Sri Lanka in order to validate the INDSERV scale. The service sector has more than a 57 percent share of gross domestic production (during 2009-2014). Telecommunication, trading, ports, hospitality and financial services are the main contributors to the growth (Source: Central Bank of Sri Lanka, website: http://www.cbsl.gov.lk/htm/english/08_stat/ stat.html). According to the pre-field study conducted, only the hotel industry has been formulating strategic partnerships with outsourcing vendors at multiple level activities as their main competitive strategy. Thus, the authors assumed that the hotel industry covers a wide range of service quality aspects in business-to-business relationships. Having identified the importance of the INDSERV scale as a measurement of B2B service quality, this study attempts to validate the scale in the Sri Lankan context.

This paper is structured in the following way. First, the literature is briefly reviewed for business-to-business service quality. Second, the research setting and chosen research methodology are discussed. Third, the analyses of the empirical research findings are presented. Fourth, managerial and theoretical implications and suggestions for future research are presented. 


\section{Literature Review}

Whipple and Frankel (2000) pointed out that the vendors' ability to meet performance expectations is a key success factor in a B2B business context. The best vendors are those that can meet the needs of the buying organization in terms of capacity, quality, technology, price, and service (Ogden 2006). Petersen, Ragatz \& Monczka (2005) attempted to measure the vendor's performance by improvements in on-time delivery, quality and responsiveness. Nevertheless, prompt delivery has been highly recognized as an important aspect of outsourcing (Chan \& Chin 2007, Rajabzadeh, Rostamy, \& Hosseini 2008, Byramjee, Bhagat, $\&$ Klein 2010). Furthermore, many authors see pricing as an important aspect of economic transactions and relationships, but different studies use different terms to measure pricing performances such as accuracy in budgeting (Rajabzadeh et al. 2008) and competitive cost of goods from the suppliers (Chan \& Chin 2007).

In addition, service quality improvements (Bettis, Bradley \& Hamel 1992, Allen \& Chandrasekhar 2000) and knowledge contributions (Cusmano, Mancusi \& Morrison 2000, Banerjee \& Williams 2009) are also used to measure a vendor's performance. Service quality is generally measured using the SERVQUAL scale, developed by Parasuraman et al. (1985, 1988). However, the appropriateness of the SERVQUAL scale is in doubt, as it is specifically designed for the B2C (business to customer) context (Gounaris 2005a, 2005b, Lee 2011). Gounaris $(2005 \mathrm{~b})$ developed a measurement instrument called INDSERV that specifically deals with business-to-business (B2B) service quality.

Gronrøos, (1984) is the pioneer in conceptualizing B2Bbusiness- to-business service quality. He claimed that service quality in a B2B context could be measured in terms of 'technical quality' and 'functional quality', which was the foundation for the development of the INDSERV scale. Referring to Gounaris (2005a, 2005b), the development of a proper scale for B2B services has evolved in the past two decades. Table 1 gives a summary of different quality aspects, identified in previous studies.

\section{Table 1: Service Quality in B2B Context}

\begin{tabular}{lc}
\hline Measure & Source Citations from: \\
\hline Technical quality /hard quality: core operation-related elements & Gronrøos, 1984 \\
Functional quality/ soft quality: interaction between individuals & Morgan 1991 \\
Process quality: quality of service delivery & \\
Outcome quality: quality of service received & Bochove 1994 \\
Potential quality: search attributes of provider's ability to perform the service (i.e. & \\
\hline vendors' ability) before the relation has actually begun & \\
\hline
\end{tabular}

Source: Gounaris (2005a) Measuring service quality in B2B services: an evaluation of the SERVQUAL scale visa versa the INDSERV scale. 


\section{NSBM Journal of Management}

Vol. 1, No. 1, January - June, 2015

The technical/hard quality and functional/soft quality represent the different quality aspects of the service delivery process. Gounaris (2005a), however, combined Gronrøos (1984), Szmigin (1993) and Morgan's (2001) ideas for the classification of process quality and established 1) hard process quality and 2) soft process quality. Combining it all, he formulated four dimensions as the INDSERV scale to measure service quality in a B2B service context. Table 2 depicts the items of the INDSERV scale.

There are 22 items, which cover potential quality, hard process quality, soft process quality and output quality that measure the vendor's performance. Moreover, with respect to the items in the INDSERV scale, they cover not only quality aspects, but also a range of other performance indicators of the vendors' service performance, compared to the scales/measures applied previously (Whipple \& Frankel 2000, Ogden 2006, Petersen et al. 2005, Chan \& Chin 2007, Selviaridis et al. 2008, Rajabzadeh et al. 2008).

Table 2: INDSERV Scale

\begin{tabular}{lll}
\hline Dimension & Code & Item \\
\hline Potential quality (PTQ) & PTQ 1 & 1. Offers full service \\
& PTQ 2 & 2. Has required personnel \\
PTQ 3 & 3. Has required facilities \\
& PTQ 4 & 4. Has required management philosophy \\
PTQ 5 & 5. Has a low personnel turn-over \\
PTQ 6 & 6. Uses network of partners/ associates \\
& HQ1 & 7. Keeps time schedules \\
& HQ2 & 8. Honours financial agreements / stays in budget \\
& HQ3 & 9. Meets deadlines \\
& HQ4 & 10. Looks at details \\
& HQ5 & 11. Understands our needs \\
Soft process quality (SQ) & 12. Accepts agreement enthusiastically \\
& SQ2 & 13. Listens to our problems \\
& SQ3 & 14. Opens to suggestions/ideas \\
& SQ4 & 15. Has pleasant personality \\
& SQ5 & 16. Argues if necessary \\
& SQ6 & 17. Looks at our interests \\
& OQ1 & 18. Reaches objectives \\
Output quality (OQ) & 19. Has a notable effect \\
& OQ3 & 20. Contributes to our sales/image \\
& 21. Is creative in terms of its offering \\
& 22. Is consistent with our strategy \\
\hline
\end{tabular}

Source: Gounaris (2005a) Measuring service quality in B2B services: an evaluation of the SERVQUAL scale visa versa the INDSERV scale, Journal of Services Marketing, 19/6, (2005, p. 427). 
The items measured using a 7-point Likert scale, ranging from $1=$ 'strongly disagree' to $7=$ 'strongly agree' in the original study.

\section{Methodology}

This study is purely quantitative and data was collected from the hotel industry in Sri Lanka. A self-administered questionnaire was developed including a demographic profile and the INDSERV scale. Firstly, the content validity of the questionnaire was assessed. The content validity is a subjective but systematic evaluation of how well the content of the scale represents the measurement task at hand. A pilot study served as a supplementary method to assure content validity. Content validity can be determined by having a panel of experts examining whether the items sufficiently describe the constructs being measured in the context of the study. Bryman and Bell (2007, p. 165) viewed it as an 'intuitive' process. The content validity of the questionnaire was tested in two rounds. Firstly, it was forwarded to peers. The group comprised twelve senior PhD students from the University of Malaya, Malaysia; University of Nagoya, Japan and the University of Otago, New Zealand. They were asked to check the appropriateness of wordings, flow of questions, or make any other suggestions, which in their opinion require improvement. Minor changes were proposed, and corrections were carried out. Secondly, the altered questionnaire was forwarded to five individuals. Three of them are academics from Malaysia and Sri Lanka, who are familiar with services management and quality management. Two professionals were selected from the hotel industry in Sri Lanka for their comments as well. The preparation of the final questionnaire considered the relevant comments of all experts.

According to the 2011 Directory (Rainbow Pages), there are 384 registered hotels in Sri Lanka. However, 81 'one star' and 24 'unclassified' hotels were omitted from the population, as the pre-field study found that these hotels are less likely to outsource due to their small size. Thus, the questionnaire was forwarded only to 279 hotels but responses were received from only 189. Six questionnaires were excluded from the analysis due to incompleteness and missing values. Thus, hundred and eighty three (183) usable completed questionnaires were subjected to the analysis. The hotel organizations were considered as the unit of analysis of the study. The respondents were middle level managers who handle the procurement system of the corresponding firm. The data analysis started with descriptive statistics. Then the INDSERV scale was subjected to an exploratory factor analysis, reliability tests and confirmatory factor analysis. 
NSBM Journal of Management

Vol. 1, No. 1, January - June, 2015

\section{Data Analysis}

Quantitative data was analyzed using Principle Component Analysis and Structural Equation Modeling (SEM) as it allows validating, refining and estimating complex relationships (Hair et al. 2006;). A total of 183 hotels were investigated. Most of the hotels studied are rated as two star (39\%), followed by three (35\%), four (24\%), and five star $(2 \%)$. The majority of respondents were middle level managers (43\%), followed by executives $(25 \%)$, and individuals who specified their designation as 'managers' (17\%). A total of 31 respondents declined to state their designation details.

The Kaiser-Mayer-Olkin measure of sampling adequacy was acceptable (0.81) and Bartlette's test of sphericity was significant, indicating that the items were correlated and suitable for factor analysis (Hair et al. 1998). With regard to the internal consistency of the scale, Cronbach's alpha was used (Table 3).

\section{Table 3: Cronbach's Alpha Reliability}

\begin{tabular}{|c|c|c|c|}
\hline Dimension/Item & $\begin{array}{l}\text { Item-Total } \\
\text { Correlation }\end{array}$ & $\begin{array}{c}\text { Cronbach's } \alpha \\
\text { if Deleted }\end{array}$ & $\begin{array}{c}\text { Cronbach's } \\
\text { Alpha }\end{array}$ \\
\hline Vendors' potential quality & & & 0.250 \\
\hline PTQ1 & .080 & $-.079^{a}$ & \\
\hline PTQ2 & -.033 & .086 & \\
\hline PTQ3 & 0.02 & 0.34 & \\
\hline PTQ4 & 0.03 & 0.45 & \\
\hline PTQ5 & .010 & .022 & \\
\hline PTQ6 & -.003 & .044 & \\
\hline Vendors' hard process quality & & & 0.797 \\
\hline HQ1 & .118 & .647 & \\
\hline HQ2 & .417 & .506 & \\
\hline HQ3 & .331 & .554 & \\
\hline HQ4 & .378 & .527 & \\
\hline HQ5 & .529 & .437 & \\
\hline Vendors' soft process quality & & & 0.725 \\
\hline SQ1 & .188 & .763 & \\
\hline SQ2 & .535 & .663 & \\
\hline SQ3 & .517 & .669 & \\
\hline SQ4 & .498 & .676 & \\
\hline SQ5 & .519 & .669 & \\
\hline SQ6 & .522 & .669 & \\
\hline Vendors' output quality & & & 0.795 \\
\hline OQ1 & .593 & .750 & \\
\hline OQ2 & .420 & .803 & \\
\hline OQ3 & .598 & .748 & \\
\hline OQ4 & .660 & .728 & \\
\hline OQ5 & .610 & .744 & \\
\hline
\end{tabular}


None of the instrument subscales except PTQ (Potential Quality) indicated any value below the threshold level of Cronbach's alpha $(\alpha=0.70)$. An item with a value that is less than 0.25 was considered as very weak, and played a very small role in conceptualizing the given factor (Nunnally 1978). Accordingly, the PTQ dimension was discarded due to a very low alpha value (0.25), and item-correlations were below the cut-off point $(0.25)$. This reflects that the context of the study (i.e., the hotel sector in Sri Lanka) does not show sufficient concern for future occurrences, and thereby demonstrates the characteristics of the 'shortterm orientation' nature in developing countries (Hofstede 1984). The reason may be high economic uncertainty in developing countries. Next, all other variables were subjected to a factor analysis. An exploratory factor analysis was performed to check the unidimensionality of the INDSERV scale. The results with cross loadings are reported in Table 4.

Table 4: Exploratory Factor Analysis for INDSERV

\begin{tabular}{|c|c|c|c|c|}
\hline \multirow[t]{2}{*}{ Items/dimensions (INDSERV) } & \multicolumn{4}{|c|}{ Component } \\
\hline & 1 & 2 & 3 & 4 \\
\hline \multicolumn{5}{|l|}{ Potential Quality } \\
\hline PTQ1 & -.159 & .104 & .655 & .110 \\
\hline PTQ2 & .089 & -.038 & .243 & -.556 \\
\hline PTQ5 & .170 & -0.47 & .063 & .620 \\
\hline PTQ6 & .403 & -.131 & -.051 & .196 \\
\hline \multicolumn{5}{|l|}{ Soft Process Quality } \\
\hline SQ1 & .064 & .205 & .166 & .566 \\
\hline SQ2 & .081 & .742 & .029 & .013 \\
\hline SQ3 & -.096 & .715 & .228 & .178 \\
\hline SQ4 & .130 & .684 & .173 & -.003 \\
\hline SQ5 & .221 & .677 & -.271 & .029 \\
\hline SQ6 & .182 & .677 & -.248 & .023 \\
\hline \multicolumn{5}{|l|}{ Hard Process Quality } \\
\hline HQ1 & -.142 & -.131 & .315 & .507 \\
\hline HQ2 & -.135 & .184 & .618 & -.135 \\
\hline HQ3 & -.334 & .145 & .549 & .046 \\
\hline HQ4 & .132 & .144 & .517 & .198 \\
\hline HQ5 & .725 & .003 & -.055 & .159 \\
\hline \multicolumn{5}{|l|}{ Output Quality } \\
\hline OQ1 & .693 & .105 & .181 & -.034 \\
\hline OQ2 & .642 & .101 & -.088 & .107 \\
\hline OQ3 & .660 & .138 & .319 & -.178 \\
\hline OQ4 & .682 & .242 & .264 & -.128 \\
\hline
\end{tabular}

1. Total variance extracted by 4 factors $=48.141 \%$

2. Extraction Method: Principal Component Analysis.

3. Rotation Method: Varimax with Kaiser Normalization 


\section{NSBM Journal of Management}

Vol. 1, No. 1, January - June, 2015

Even though unidimensionality is not well demonstrated in the scale (except soft process quality and output quality dimensions), EFA created four factors. The number of factors generated is well aligned to the original scale developed by Gounaris (2005a). These four factors explain only 48.141 per cent of total variance, which is considerably low. The PTQ (i.e. potential quality) items are scattered among three factors and this results in poor discriminant validity. Furthermore, SQ1, HQ1 and HQ5 deviated from the theoretically defined location. With respect to the factor loadings, PTQ6 is determined to be below 0.5 .

The deletion of items due to statistical issues is not advisable in the beginning (Hair et al. 2006), as this may affect construct validity. Then, the scale was subjected to a confirmatory factor analysis to assess convergent validity, composite reliability and discriminant validity. The first order measurement model for INDSERV is shown in Figure 1.

\section{Figure 1: $1^{\text {st }}$ order Measurement Model for INDSERV}

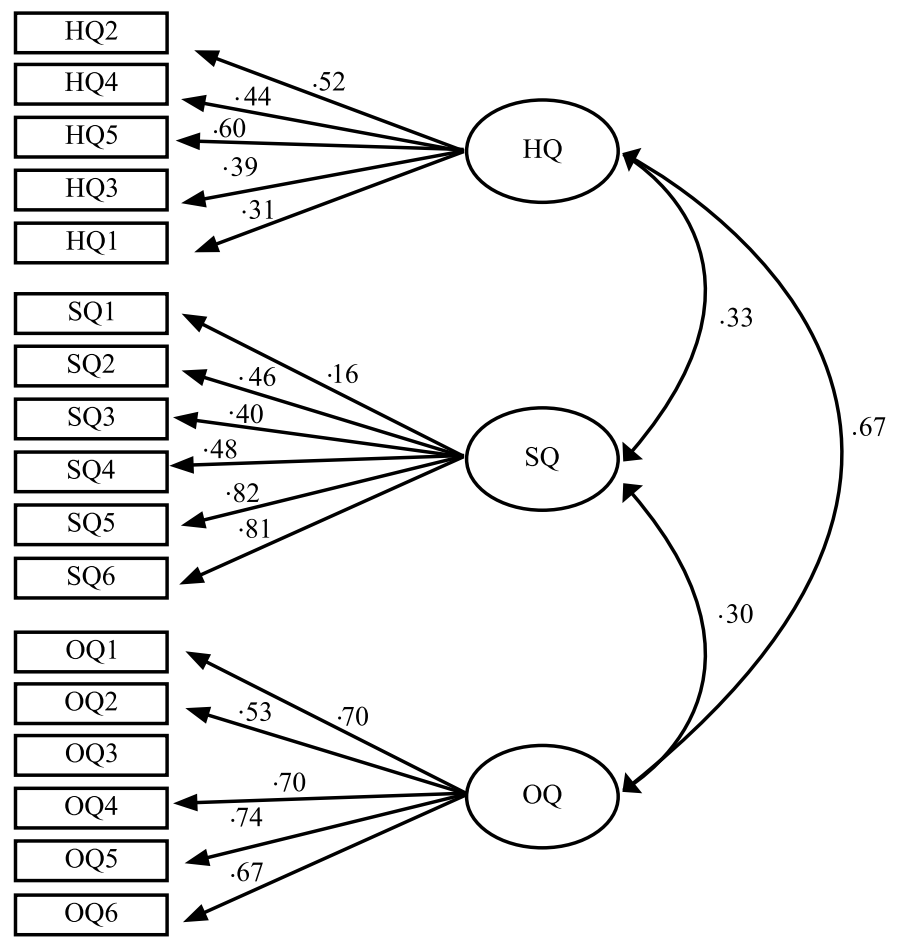

HQ1, 3, 4; SQ1, 2, 3, 4 report standardized regression weights below 0.5, and subsequently, a step-wise deletion of items starting from the lowest standardized regression weight was conducted. 
For instance, SQ1 reports the lowest value (0.16) and hence was discarded first, followed by HQ1, HQ2 and HQ3 in successive stages. Ultimately, the INDSERV model was refined, as depicted in Figure 2. The refined model represents 'Hoelter's critical N' for 0.5 as 160 , and 0.1 as 180 , which confirms the adequacy of the sample for the model (Hair et al. 2006). However, the refined model (in Figure 2) contains items with low (i.e., HQ3 and SQ4) and marginal convergence validity (i.e., HQ4, HQ5 and OQ2).

Indeed, these items will affect Average Variance Extracted (AVE) and discriminant validity of the latent variables/construct. But the study still wishes to maintain them, as the deletion of further items could seriously affect the content validity of the INDSERV scale. The above results indicate a mismatch of the scale in the South Asian context.

\section{Figure 2: Purified 1st Order Measurement Model for INDSERV}

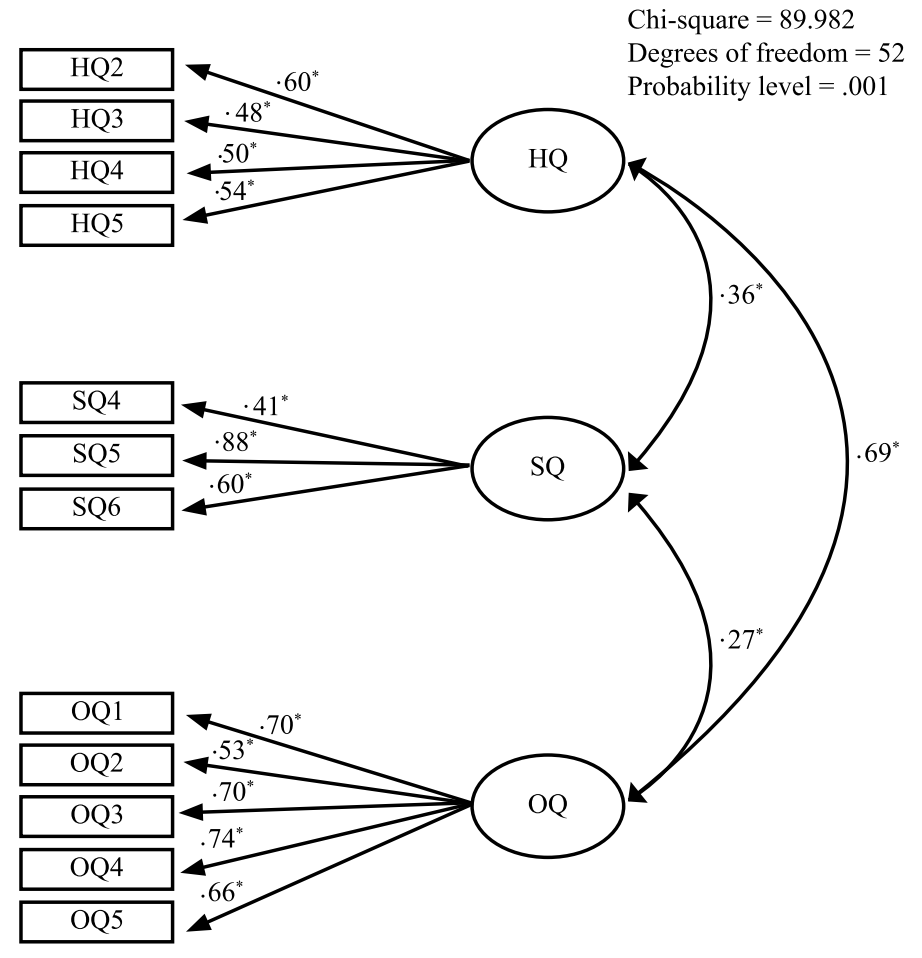

*Factor loadings are significant at 0.05 level 
NSBM Journal of Management

Vol. 1, No. 1, January - June, 2015

Table 5: Goodness of fit indices of INDSERV

\begin{tabular}{ccccccc}
\hline \multicolumn{4}{c}{ Absolutes } & \multicolumn{3}{c}{ Incremental } \\
\hline CIMIN/DF & GFI & AGFI & RMSEA & IFI & TLI & CFI \\
\hline 1.730 & .940 & .910 & .060 & .947 & .931 & .946 \\
\hline
\end{tabular}

According to Table 5, the absolute fit indices confirm the fit between the observed data and the model. The RMSEA is within the range of 0.05- 0.08, indicating that badness of fit of the model is negligible (Hair et al. 1998). Then, incremental indices are above 0.9, confirming that the construct fits the baseline model, assuming that all observed variables are uncorrelated (Hair et al. 2006, p.749). Based on the factor loadings reported in the refined model, the convergent and discriminant validity was assessed with the Average Variance Extracted (AVE) and Composite Reliability (CR) accordingly. Table 6 reports CR values with SMC and AVE matrix for Discriminant Validity.

Table 6: Validity and Reliability Summary

\begin{tabular}{cccc|ccc}
\hline Variable & Mean & CR & AVE & SQ & HQ & OQ \\
\hline SQ & 4.56 & 0.75 & 0.53 & $\mathbf{0 . 5 3}$ & & \\
HQ & 5.31 & 0.83 & 0.32 & .113 & $\mathbf{0 . 3 2}$ & \\
OQ & 5.56 & 0.87 & 0.45 & 0.78 & $\mathbf{. 4 7 6}$ & $\mathbf{0 . 4 5}$ \\
\hline
\end{tabular}

The AVE of less than 0.5 shows that, on average, more errors remain in the item than variance explained by the latent factor structure imposed on the measure (Hair et al. 2006). Table 06 shows two variables $(\mathrm{HQ}=.32, \mathrm{OQ}=.45)$ having lower convergence validity (AVE). In relation to HQ and OQ, they are considered acceptable, as not only the direct paths between these items and their respective latent variables indicate significant $\mathrm{p}$-values, but they could also maintain a satisfactory level of composite reliability (CR). The results in Table 06 indicate good CR values for all dimensions of INDSERV.

With regard to discriminant validity, Hard process Quality (HQ) is weak in discriminating its own items from other constructs. This outcome was expected, as some items of HQ variable do not sufficiently maintain their convergence validity. As noted above, those items are kept in the scale, as it otherwise severely affects content validity. 
The SMC value between HQ and SQ (0.476) is higher than the AVE of Hard process Quality (0.32). This implies that the discriminant validity of Hard process Quality (HQ) is unsatisfactory. With reference to Table 04, there are two items (i.e. HQ 1 and HQ 5) of the dimension loaded into two different factors disturbing the unidimensionality of the HQ. Thus, from the beginning of scale refinement, the scale demonstrated issues of reliability and validity.

\section{Discussion}

However, the INDSERV scale was developed in the Western context. In the original study, INDSERV showed satisfactory reliability and validity (Gounaris 2005a). It also reported superior psychometric properties in SERVQUAL (Lee 2011, p. 3180). However, in the present study the scale reported many reliability and validity issues. As a result one dimension as a whole and some items were excluded. This study provides evidence of a contextual mismatch of borrowed scales from a different cultural context. All deleted items are listed in Table 7.

\section{Table 7: Deleted Items in INDSERV Scale}

\begin{tabular}{lll}
\hline Dimension & Items & Description \\
\hline Potential Quality & PTQ 1 & Offers full service \\
PTQ 2 & Has required personnel \\
PTQ 3 & Has required facilities \\
PTQ 4 & Has required management philosophy \\
PTQ 5 & Has a low personnel turn-over \\
& PTQ 6 & Uses network of partners/ associates \\
Hard process Quality & HQ 1 & Keeps time schedules \\
Soft process Quality & SQ 1 & Accept agreement enthusiastically \\
& SQ 2 & Listen to our problems \\
& SQ 3 & Opened to suggestions/ideas \\
\hline
\end{tabular}

According to Table 7, it is clear that the context of the study does not oversee a value of 'potential quality' of the vendor in assessing their performance. This might reflect that the context of the study (i.e., Sri Lanka) does not show sufficient concern for future occurrences, and thereby demonstrates the characteristics of the 'short-term orientation' nature of developing countries (Hofstade 1984). The reason may be high economic uncertainty in developing countries. Therefore, 22-item INDSERV scale shows a contextual mismatch. Despite these facts, Lee (2011) stated that the dimensions of INDSERV are interconnected. 


\section{NSBM Journal of Management}

Vol. 1, No. 1, January - June, 2015

He empirically justified that soft process quality (SQ) and hard process quality (HQ) are the mediators between potential quality and output quality rather than their independent roles. Among the dimensions remaining in the scale, hard process quality (HQ) shows the highest contribution on the INDSERV $(\beta=0.98, \mathrm{R} 2=96.5 \%$ ) followed by output quality ( $\beta=0.86$, $\mathrm{R} 2=74 \%$ ). With reference to the factor loadings in Figure 02, the prominent service quality characteristics of a vendor are: argues when necessary (SQ5, $\lambda=.88$ ), looks at the focal firm's interests (SQ $6, \lambda=.81$ ), have creative offerings (OQ4, $\lambda=.74$ ), reaches objectives (OQ1, $\lambda$ $=.70$ ), and contributes to the focal firm image (OQ3, $\lambda=.70)$.

\section{Conclusion}

The vendors' market is also competitive; hence they have to strive for survival. The INDSERV scale provides general guidelines for vendors about the expectations of the focal firm in the business-to-business context (Gounaris 2005a). But as far as the study context is concerned, not all elements are equally important and valid. Accordingly, vendors in the study context can focus more on the refined elements of the INDSERV scale (in Figure 2). Further, the focal firms (i.e., hotels in this study) are more likely to assess output and soft process quality aspects rather than hard process quality and potential quality in measuring their vendor's service quality performance. The vendors' potential quality however becomes invalid in the hotel sector in Sri Lanka possibly for many reasons such as economic uncertainty, short-term orientation, etc. Anyhow, these factors need to be empirically tested.

Having identified that the findings of this study are limited to the hotel sector in Sri Lanka, future research could validate the INDSERV scale in different contexts with data from different service industries. The present study further recommends performing exploratory studies to discover unique service quality dimensions in the business-to-business context in Sri Lanka. More specifically in-depth interviews and focus group discussions with focal firms and vendors will help find new quality dimensions/aspects. This study highlights the recommendation of the use of localized scales when the research context is considerably different from the context where the scale originated. 


\section{References}

Al-Natour, S \& Cavusoglu, H 2009, 'The strategic knowledge-based dependency diagrams: a tool for analyzing strategic knowledge dependencies for the purposes of understanding and communicating' Information Technology Management, vol. 10, 103-121.

Bettis, RA, Bradley, SP \& Hamel, G 1992, 'Outsourcing and industrial decline', Academy of Management Executive, vol. 6, no. 1 pp. 7-22.

Banerjee, A \& Williams, SA 2009, 'Industry insight, international service outsourcing using offshore analytics to identify determinants of value-added outsourcing. Strategic Outsourcing: An International Journal, vol. 2, no. 1, pp.1 68-79.

Byramjee, F, Bhagat, P \& Klein, A 2010, 'The moderating role of relationship quality in determining total value orientation'. Global Journal of Business Research, vol. 4, no. 2, pp. 49-62.

Chan, TCT \& Chin, KS 2007, 'Key success factors of strategic sourcing: an empirical study of the Hong Kong toy industry', Industrial Management \& Data Systems, vol. 107, no. 9, pp. 1391-1416.

Cusmano, L, Mancusi, ML, \& Morrison, A 2009, 'Innovation and the geographical and organizational dimensions of outsourcing: evidence from Italian firm-level data'. Journal of Structural Change and Economic Dynamics, vol. 20, pp. 183-195.

Gounaris, S 2005a, 'Measuring service quality in b2b services: an evaluation of the SERVQUAL scale vis-a-vis the INDSERV scale'. Journal of Services Marketing, vol. 19, no. 6, pp. 421-435.

Gounaris, S 2005b, 'An alternative measure for assessing perceived quality of software house services', The Service Industries Journal, vol. 25, no. 6, pp. 803-823.

Grönroos, C 1984, 'A Service Quality Model and its Marketing Implications', European Journal of Marketing, vol. 18, no. 4, pp. 36-44.

Hair, JF, Anderson, RE, Tatham, RL \& Black, WC 1998, Multivariate Data Analysis 5th edn, New Jersey: Prentice Hall.

Hair, JF, Black, WC, Babin, BJ, Anderson, RE \& Tatham, RL 2006, Multivariate data analysis, 5 th edn, Prentice Hall, New Jersey.

Hair, JF, Black, WC, Babin, BJ, \& Anderson, R E 2010, Multivariate Data Analysis. Pearson Education, New Jersey.

Hofstede, G 1984, 'The cultural relativity of the quality of life concept'. Academy of Management Review, vol. 9, pp. 389-398.

Lee, GJ 2011, 'Measuring business-to-business customer service: a structural re-examination of the INDSERV scale.' African Journal of Business Management, vol. 5, vol. 8, pp. 3179-3187.

Morgan, GA, Griego, OV \& Gloeckner, G 2001, SPSS for Windows: An Introduction to Use and Interpretation in Research, Lawrence Erlbaum Associates, New Jersey.

Nunnally, JC 1978, Psychometric theory, 2nd edn, New York: McGraw-Hill.

Ogden, JA 2006, 'Supply Base Reduction: an empirical study of critical success factors', Journal of Supply Chain Management, vol. 42, no. 4, pp. 29-39. 


\section{NSBM Journal of Management}

Vol. 1, No. 1, January - June, 2015

Parasuraman, A, Berry, LL \& Zeithaml, VA 1985, 'A conceptual model of service quality and implications for future research', Journal of Marketing, vol. 49 (Fall), pp. 41-50.

Parasuraman, A, Zeithaml, VA \& Berry, LL 1988, 'SERVQUAL: A Multiple-Item Scale for Measuring Consumer Perceptions of Service Quality', Journal of Retailing, vol.64, no. 1, pp. 12-40.

Petersen, KJ, Ragatz, GL \& Monczka, RM 2005, 'An examination of collaborative planning effectiveness and supply chain performance', Journal of Supply Chain Management, vol. 41, no. 2, pp 14-25.

Rajabzadeh, A, Rostamy, AAA \& Hosseini, A 2008, 'Designing a generic model for outsourcing process in public sector: evidence of Iran', Management Decision, vol.46, no. 4, pp. 521-538.

Selviaridis, K, Spring, M, Profillidis, V \& Botzoris, G 2008, 'Benefits, risks, selection criteria and success factors for third-party logistics services', Maritime Economics \& Logistics, vol. 1 pp. 380-392.

Whipple, MJ \& Frankel, R 2000, 'Strategic alliance success factors', Journal of Supply Chain Management, vol. 36, no. 3 pp. 21-28. 